\title{
Quantificação das Substâncias Fenólicas Totais em Órgãos da Aroeira Schinus terebenthifolius (RADDI)
}

\author{
Luís Carlos Soares Queires $^{1}$ and Luiz Erlon Araujo Rodrigues ${ }^{* 2}$ \\ ${ }^{1}$ Departamento de Ciências Exatas e da Terra, - UNEB, Alagoinhas, Bahia; ${ }^{2}$ Departamento de Biofunção do \\ Instituto de Ciências da Saúde, Universidade Federal da Bahia, Caixa Postal 4747, Salvador, CEP 40.155-51 \\ Bahia, Brasil
}

\begin{abstract}
The "aroeira" (Schinus terebenthifolius, RADDI), known as a toxic plant is actually very used in popular medicine, mainly in the treatment of general inflammatory processes. Many of its properties or of its curative effects may be attributed to the different polyphenols that belong to its structural constitution. In this work we have demonstrated that the distribution of total phenols was different in the several organs of the "aroeira", such as leaves, flowers, fruits and stem. The importance of these substances for the plant physiology and defense mechanisms, their ecological relationships and some therapeutic uses were also discussed. The correlation between the polyphenol properties and the metabolism of animal cells, suggest special attention when the infusions or hydroalcoholic extracts, obtained from that plant, are used in humans.
\end{abstract}

Key words: Phenolic substances, Aroeira, Schinus terebenthifolius

\section{INTRODUÇÃO}

Pertencente à família das anacardiáceas, a aroeira vermelha, Schinus terebenthifolius (RADDI), é apreciada pela boa qualidade de sua madeira e, na medicina popular, usada no tratamento dos processos inflamatórios em geral, úlceras da pele e diarréias. Na maioria desses empregos terapêuticos, usa-se o extrato aquoso bruto, obtido da casca, do caule e de suas folhas. É considerada, no meio popular, como uma planta tóxica porque contém princípios ativos hipersensibilizantes. Relatos feitos por (Cruz, 1982) indicaram que certas pessoas podem desenvolver irritações da pele, prurido, urticária, febre e transtornos visuais, quando em contato mais íntimo com a planta. Sua resina contém traços de óleos voláteis que apresentam felandrenos, carvacrol e pinenos. Esta última substância, provavelmente, confere a propriedade picante característica dos extratos desta planta (Schvartsman, 1979).
Candela et al. (1995) demonstraram que a resistência de três cultivares de Capsicum annuum à infecção pelo Phytophora capsici deve-se, muito provavelmente, ao efeito inibitório no crescimento deste fungo, provocado pelo ácido trans-cinâmico e pelos fenóis, $p$-hidroxibenzóico, vanílico e salicílico. A resistência do lenho da aroeira do sertão (Astronium orindeuva) à decomposição parece ser decorrente, também, da presença de substâncias fenólicas em sua constituição. Tais substâncias podem ser responsáveis pela maioria das qualidades úteis destas espécies, como fontes naturais de fenóis para a indústria, além da capacidade de influenciar na interação ecológica desta espécie com outras. Matsuki (1996) resume esta regulação biossintética, a nível molecular e bioquímico. A síntese dos compostos fenólicos nos vegetais, é dependente do estágio de desenvolvimento do órgão e,

\footnotetext{
* Autor para correspondencia
} 
também, pode ser induzida por fatores exógenos.

Na indústria alimentícia, os compostos fenólicos contribuem para a estabilidade dos óleos (Maestroduran, 1994) e nos vinhos para cores mais estáveis e gostos característicos (Zamora et $a l ., 1995)$. Com relação à indústria de madeira, Santana et al. (1995) verificaram que o tanino da acácia pode substituir os fenóis de origem petrolífera, repondo cerca de $33 \%$ do fenol na

\section{MATERIAL E MÉTODO}

Amostras foram constituídas de folhas adultas, flores, frutos com cerca de $4 \mathrm{~mm}$ de diâmetro e do caule, o córtex e o lenho. As porções foram retiradas de uma população de $S$. terebentifolius com altura média de três metros, localizada nos limites do Campus da Universidade do Estado da Bahia, situada na cidade de Alagoinhas, a $12^{\circ} 08^{\prime} 01^{\prime \prime}$ de latitude sul e $38^{\circ} 25^{\prime} 25^{\prime \prime}$ de longitude oeste. Imediatamente após a colheita, as amostras foram separadas e acondicionadas em sacos plásticos, sob pressão negativa $\mathrm{e}$ mantidas congeladas a $-20^{\circ} \mathrm{C}$ até as subseqüentes análises.

Os fenóis foram extraídos macerando-se $50 \mathrm{mg}$ de cada amostra em homogeneizador tipo "waring blendor", segundo Torti et al. (1995); com $10 \mathrm{~mL}$ de etanol a $70 \%(\mathrm{v} / \mathrm{v})$, (Mattos, 1988).

\section{RESULTADOS}

A distribuição dos fenóis nos diversos órgãos que constituem a parte aérea da aroeira é quantitativamente variável. A tabela 1 mostra os valores médios encontrados, com base no peso úmido (P.U.). O fruto apresentou o menor valor, $9,54 \pm 2,33 \mathrm{mg}$ de fenóis totais/g de peso úmido. preparação de adesivos aplicados no fabrico de compensados de madeira.

Diante do exposto, pretendemos demonstrar, dentre as diversas espécies de aroeira e devido a utilização de suas folhas e cascas como medicamento popular, a distribuição das substâncias fenólicas solúveis totais nos diversos órgãos que constituem a parte aérea de S. terebentifolius, espécie típica da vegetação do cerrado.

O homogeneizado total foi submetido a centrifugação a $1000 \mathrm{~g}$ durante dez minutos. Ao sobrenadante, juntou-se $2 \mathrm{~mL}$ de tungstato de sódio a $3 \times 10^{-1} \mathrm{M}$ e igual volume de ácido sulfúrico $66 \times 10^{-2} \mathrm{~N}$. Após agitação, para a precipitação das proteínas totais, efetuou-se nova centrifugação, semelhante à anterior. Os fenóis totais foram dosados nos extratos hidroalcoólicos correspondentes aos últimos sobrenadantes obtido para cada amostra, utilizando-se o reagente de Folin segundo por Lowry et al. (1951). As absorvâncias foram medidas em espectrofotômetro Carls Zeiss-Jena, a $560 \mathrm{~nm}$, plotando-se os resultados em curvapadrão feita com fenol comum.

Os dados foram submetidos a análise de variância e ao teste de Student-Newman-Keuls. Foram considerados significantes os valores de $\mathrm{p}<0,05$.

Por sua vez, o lenho mostrou o teor de $18,12^{ \pm}$ 3,33 $\mathrm{mg}$ de fenóis/g. A diferença entre esses dois valores foi significativa $(p<0,05)$. O teor de fenóis totais encontrados nas folhas foi, em média, de 40,32 $\pm 8,41 \mathrm{mg} / \mathrm{g}$. Este valor foi 
superado apenas por aquele presente nas flores:

Tabela 1. Quantidade média de fenóis nos órgãos da aroeira. Médias aritméticas de $n=25$ e seus respectivos desvios padrões.

\begin{tabular}{|l|c|}
\hline Parte aérea & mg de fenol/g P.U. \\
\hline Fruto & $9,54 \pm 2,33$ \\
\hline Flor & $43,79 \pm 4,48$ \\
\hline Folha & $40,32 \pm 8,41$ \\
\hline Caule córtex & $32,10 \pm 3,61$ \\
\hline Caule lenho & $18,12 \pm 3,33$ \\
\hline
\end{tabular}

As diferenças entre os valores de fenóis totais encontrados nos diversos órgãos examinados apresentaram significâncias estatísticas $(\mathrm{p}<0,05)$ quando comparadas entre si. Somente a comparação entre os valores das folhas e das flores não foi estatisticamente significante. No que se refere ao ciclo de vida da planta, as
$43,79 \pm 4,48 \mathrm{mg} / \mathrm{g}$.

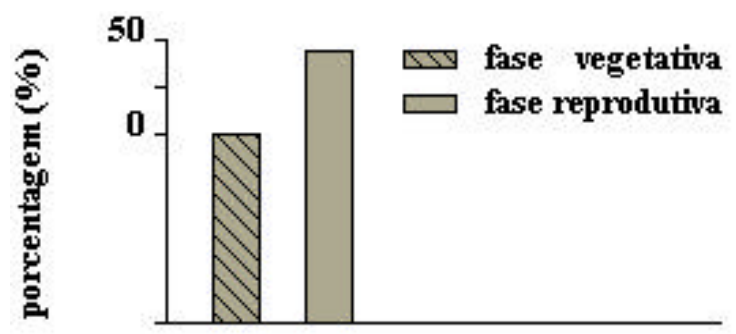

Figura 1. Aumento percentual da fase reprodutiva em relação à vegetativa

partes vegetativas mostraram, segundo a soma dos valores expressos na Tabela 2, que os teores fenólicos dosados totalizaram 62,93\%. Os principais responsáveis por este alcance foram as folhas com $28,03 \%$ e o córtex do caule com $22,31 \%$.

Tabela 2. Percentuais dos fenóis totais encontrado no extrato hidroalcoólico de diversos órgãos da aroeira.

\begin{tabular}{||l|l|c|c|}
\hline \multirow{2}{*}{ Parte aérea } & \multicolumn{2}{c|}{ Fenóis solúveis totais (\%) } \\
\cline { 3 - 4 } & Caule lenho & Partes individuais & Somatório \\
\hline \multirow{3}{*}{ Órgãos vegetativos } & Caule córtex & $\mathbf{1 2 , 5 9}$ & \multirow{2}{*}{62,93} \\
\cline { 2 - 3 } & Folha & 22,31 & \\
\hline \multirow{2}{*}{ Órgãos reprodutivos } & Fruto & $\mathbf{6 , 6 3}$ & \multirow{2}{*}{37,07} \\
\cline { 2 - 3 } & Flor & $\mathbf{3 0 , 4 4}$ & \\
\hline
\end{tabular}

A figura 1 exibe a comparação feita, por unidade de peso úmido, entre as fases vegetativa e reprodutiva do desenvolvimento da planta. Elas se distingem pela presença de flores e frutos. $\mathrm{O}$ período reprodutivo exibiu um acréscimo de $41,1 \%$ em relação ao total dos fenóis dosados na fase vegetativa.

\section{DISCUSSÃO}

As substâncias fenólicas biossintetizadas nos vegetais são produtos do metabolismo secundário. A variação dos teores fenólicos na parte aérea da aroeira está de acordo com a revisão feita por Matsuki (1996), o qual relata que diferentes tipos celulares podem regular sua própria síntese fenólica. As duas médias encontradas no caule, respectivamente, do córtex (floema) e do lenho (xilema), exprimem a atividade metabólica destes tecidos. Porque o tecido xilemático é formado principalmente de células traqueais e quando na sua maturidade elas não têm protoplasma (Esau, 1981), parte do teor dos fenóis $(18,12 \pm 3,33 \mathrm{mg})$ pode está contida na parede celular remanescente. Miyamoto e Schopfer (1997) concluíram que os 
constituintes fenólicos poliméricos da parede celular estão sujeitos à degradação. Nesta mesma estrutura, em Nicotiana tabacum, Richardson e Mcdougall (1997) comprovaram atividade oxidásica polifenólica. Segundo Zhang e Chiang (1997), outra enzima também presente na parede celular, é a 4-coumarato-CoA ligase ou 4-coumaroil-CoA sintetase, E.C. 6.2.1.12, responsável pela biossíntese do ácido $p$ hidroxicinâmico, importante metabólito fenólico na fabricação da lignina.

O floema atua principalmente na distribuição das substâncias produzidas nas folhas, a exemplo da translação dos produtos do metabolismo secundário. As flores apresentaram a menor diferença em relação à média obtida pelas folhas. Aqueles órgãos são também irrigados pelo floema e, por conseqüência, podem receber fenóis diretamente das folhas. Basu e Chand (1996) detectaram antocianidinas em flores de Hyoscyamus muticus. Os vários componentes desse grupo químico encontrados como responsáveis pela coloração das flores são próprios da espécie. Os resultados obtidos por Davies e Mazza (1993) concernentes à coloração das flores mostraram que os matizes da Monarda fistulosa são influenciadas pelo $\mathrm{pH}$ assim como pela concentração dos pigmentos antociânicos e dos co-pigmentos, a exemplo dos polifenóis, alcalóides e aminoácidos. Vanwyk et al. (1997) demonstraram também que a pigmentação das flores do gênero Lobostemon (boragináceas) resultaram das variações dos diversos tipos de glicosídios da delfinidina. Os resultados experimentais deste trabalho mostraram que na fase reprodutiva da aroeira, houve um acréscimo de $41,1 \%$ dos fenóis totais. As flores atingiram o maior percentual de fenóis totais $(30,44 \%)$. Provavelmente estes resultados são devidos aos diversos tipos de polifenóis ou dos seus conjugados, presentes nestes órgãos reprodutivos.

Durante o desenvolvimento do fruto do tomateiro e principalmente na fase do amadurecimento, a polpa e o pericarpo apresentaram níveis decrescentes do ácido clorogênico e da auxina (ácido indol-3-acético) (Buta e Spaulding, 1997). Os resultados deste trabalho sugerem que os frutos da aroeira estariam entrando na fase de maturação, porque apontam os menores valores dos fenóis totais dosados. Como o desenvolvimento de qualquer órgão vegetal está sob controle hormonal, Hagendoorn et al. (1997) verificaram que baixas concentrações de auxina em Morinda citrifolia aumentaram a produção de antraquinona e diminuíram a taxa de crescimento.

De acordo com Matsuki (1996), a síntese de certos compostos fenólicos pode ser induzida por fatores ambientes, a exemplo da intensidade luminosa, fertilidade do solo e de fatores biológicos. Experimentos realizados "in vitro" por Silva et al. (1996) revelaram que o ácido ferúlico inibiu a atividade da urease da soja (E.C. 3.5.1.5) em cerca de 36,9\%. Observações de Orians e Floyd (1997) no tocante à nutrição das plantas de Salix eriocephala e S. sericea mostram que o aumento da susceptibilidade a herbívoros e patógenos foi diretamente proporcional às quantidades do fertilizante aplicado. Sallaud et al. (1997) verificaram que no local da infecção das folhas de alfafa pela Pseudomonas syringae ocorreu o acúmulo de flavonóides, enquanto que a medicarpina, uma fitoalexina fenólica antifúngica, produzidas por leguminosas, manteve-se em nível muito baixo. A acumulação de vários tipos de substâncias em resposta à uma infecção são muito estudadas atualmente. Hipskind et al. (1996) concluíram que a resposta à infecção por Bipolares maydis provocou o acúmulo de antocianidinas nas células saudáveis que rodeiam o local infectado pelo patógeno, restringindo a infecção. O início da micorrização em cevada produziu uma acumulação de amidas como resposta defensiva (Peipp, 1997). Contudo, Shirasu et al. (1997) propuseram que o ácido salicílico funciona como um importante sinal químico no controle da indução dos mecanismos de resistências às doenças.

A importância dos fenóis na interação de diversas espécies de insetos e plantas tem importantes implicações ecológicas. Um desses exemplos é a atração de insetos, induzida pela coloração das flores. Konno et al. (1997) observaram que as folhas das quais o lepdóptero (Ligustrum obtusifolium) se alimenta, apresentam uma extrema atividade desnaturante 
de proteínas, possivelmente ligada a polifenóis que as constituem. Estes autores sugeriram que a alta secreção de glicina encontrada nos sucos digestivos dessas larvas serviria como mecanismo de defesa devido à qualidade do seu regime alimentar.

Segundo Frantz et al. (1996) os fenóis derivados do metabolismo do benzeno são inibidores da atividade enzimática da topoisomerase II (DNA girase, E.C. 5.99.1.3), enzima que rearranja as hélices do DNA. Resultados obtidos por Gut et al. (1996) indicaram que as quinonas podem destruir o citocromo $\mathrm{P} 450$ da fração microssômica do fígado humano. Após propor diversas hipóteses sobre os metabólitos do catabolismo do benzeno, na indução de alguns tipos de câncer, Smith (1996) sugere que os compostos fenólicos e quinônicos são potenciais indutores de leucemia no homem. Estes estudos

\section{CONCLUSÕES}

Os diversos órgãos da aroeira diferiram significativamente em suas quantidades de fenóis. Teores encontrados no lenho caulinar demonstraram uma considerável atividade metabólica desse tecido.

A flor apresentou o maior valor por unidade de peso úmido. Esse achado parece relacionar-se a

\section{REFERÊNCIAS}

Basu, P. \& Chand, S. (1996), Anthocyanin accumulation in Hyoscyamus muticus $\mathrm{L}$. tissue cultures. J. Biotechnol., 52(2): 151159.

Buta, J.G. \& Spaulding, D.W. (1997), Endogenous levels of phenolics in tomato fruit during growth and maturation. J. Plant Growth Regul., 16(1): 43-46.

Candela, M.E.; Alcazar, M.D.; Espin, A. \& Almela, L. (1995), Soluble phenolic acids in Capsicum annuum stems infected with Phytophthora capsici. Plant Pathol., 44(1): 116-123. explicam a provável toxidade que pode decorrer da ingestão de órgãos vegetais "in natura" ou de suas infusões.

Os fenóis também apresentam efeitos benéficos para o homem. Herman et al. (1995) observaram que os glicosídios de isoflavonóides, convertidos por bactérias intestinais, possuem uma fraca atividade estrogênica e antioxidativa e sugeriram que os isoflavonóides difenólicos, naturais da soja, têm propriedades antineoplásicas. Frankel et al. (1995) demonstraram a atividade antioxidativa dos vinhos, sobre as lipoproteínas de baixa densidade em humanos. Manna et al. (1997) sugeriram que a absorção de polifenóis do óleo de oliva pode diminuir o risco de doenças relacionadas a distúrbios gastrointestinais e a ateroesclerose.

mecanismos de defesa e de interação. Tendo em vista os efeitos nocivos dos polifenóis, para o metabolismo celular dos animais, o emprego dos órgãos da aroeira na medicina popular, quer na forma de extrato hidroalcoólico ou de infusão, necessita de cuidados especiais e deve ser melhor avaliado.

Cruz, G.L. (1982), Aroeira In: Dicionário das Plantas Úteis do Brasil, 2 ${ }^{-}$Ed., Rio de Janeiro, Civilização Brasileira, pp. 70-72.

Davies, A.J. \& Mazza, G. (1993), Copigmentation of simple and acylated anthocyanins with colorless phenolic compounds. J. Agric. Food Chem., 41(5): 716-720.

Esau, K. (1981), Xilema: estrutura geral e tipos de células. In: Anatomia das Plantas com Sementes, Trad. Berta Lange de Morretes, São Paulo, Edgard Blücher, pp. 59-73.

Frankel, E.N.; Waterhouse, A.L. \& Teissedre, P.L. (1995), Principal phenolic phytochemicals in selected California wines 
and their antioxidant activity in inhibiting oxidation of human low-density lipoproteins. J. Agric. Food Chem., 43(4): 890-894.

Frantz, C.E.; Chen, H.W. \& Eastmond, D.A. (1996), Inhibition of human topoisomerase II in vitro by bioactive benzene metabolites. Environ. Health Perspect., 104(6): 13191323.

Gut, I.; Nedelcheva, V.; Soucek, P.; Stopka, P. \& Tichavska, B. (1996), Cytochromes P450 in benzene metabolism and involvement of their metabolites and reactive oxygen species in toxicity. Environ. Health Perspect., 104(6): 1211-1218.

Hagendoorn, M.J.M.; Jamar, D.C.L.; Meykamp, B. \& Vanderplas, L.H.W. (1997), Cell division versus secondary metabolite production in Morinda citrifolia cell suspensions. J. Plant Physiol., 150(3): 325330.

Herman, C.; Adlercreutz, T.; Goldin, B.R.; Gorbach, S.L.; Hockerstedt, K.A.V.; Watanab, S.; Hamalainen, E.K.; Markkanen, M.H.; Makela, T.H.; Wahala, K.T.; Hase, T.A. \& Fotsis, T. (1995), Soybean phytoestrogen intake and cancer risk. J. Nut., 125(3): 757-770.

Hipskind, J.; Wood, K. \& Nicholson, R.L. (1996), Localized stimulation of anthocyanin accumulation and delineation of pathogen ingress in maize genetically resistant to Bipolaris maydis race O. Physiol. Molec. Plant Pathol., 49(4): 247-256.

Konno, K.; Hirayama, C. \& Shinbo, H. (1997), Glycine in digestive juice: a strategy of herbivorous insects against chemical defense of host plants. J. Insect. Physiol., 43(3): 217224.

Lowry, O.H.; Rosenbrough, N.R.; Farr, A.L. \& Randall, R.J. (1951), Protein measurement with Folin-phenol reagent. J. Biol. Chem., 139: 265-275.

Maestroduran, R.; Cabello, R.L. \& Gutierrez, V.R. (1994), Phenolic compounds from olive (Olea europaea). Grasas y Aceites, 45(4): 265-269.

Manna, C.; Galletti, P.; Cucciolla, V.; Moltedo, O.; Leone, A. \& Zappia, V. (1997), The protective effect of the olive oil polyphenol (3,4-dihydroxyphenyl) ethanol counteracts reactive oxygen metabolite-induced cytotoxicity in Caco-2 cells. J. Nutr., 127(2): 286-292.

Matsuki, M. (1996), Regulation of plant phenolic synthesis: from biochemistry to ecology and evolution. Aust. J. Bot., 44(6): 613-634.

Mattos, F.J.A. (1988), Roteiro seqüencial de prospeção de constituintes químicos de extratos de plantas. In: Introdução à Fitoquímica Experimental, Fortaleza, Edições da Universidade Federal do Ceará, pp. 35-66.

Miyamoto, K. \& Schopfer, P. (1997), Release of UV-absorbing substances from maize coleoptiles during auxin-, fusicoccin- and acid-mediated elongation growth. J. Plant Physiol., 150(3): 317-324.

Orians, C.M. \& Floyd, T. (1997), The susceptibility of parental and hybrid willows to plant enemies under contrasting soil nutrient conditions. Oecologia, 109(3): 407413.

Peipp, H.; Maier, W.; Schmidt, J.; Wray, V. \& Strack, D. (1997), Arbuscular mycorrhizal fungus-induced changes in the accumulation of secondary compounds in barley roots. Phytochemistry, 44(4): 581-587.

Richardson, A. \& Mcdougall, G.J. (1997), A laccase-type polyphenol oxidase from lignifying xylem of tobacco. Phytochemistry, 44(2): 229-235.

Sallaud, C.; Zuanazzi, J.; Elturk, J.; Leymarie, J.; Breda, C.; Buffard, D.; Dekozak, I.; Ratet, P.; Husson, P.; Kondorosi, A. \& Esnault, R. (1997), Gene expression is not systematically linked to phytoalexin production during alfalfa leaf interaction with pathogenic bacteria. Mol. Plant Microbe Inter., 10(2): 257-267.

Santana, M.A.E.; Baumann, M.G.D. \& Conner, A.H. (1995), Resol resins prepared with tannin liquified in phenol. Holzforschung, 49(2): 146-152.

Schvartsman, S. (1979), Anacardiaceae In: Plantas Venenosas, S. Paulo, Savier,, pp. 4952.

Shirasu, K.; Nakajima, H.; Rajasekhar, V.K.; Dixon, R.A. \& Lamb, C. (1997), Salicylic acid potentiates an agonist-dependent gain control that amplifies pathogen signals in the 
activation of defense mechanisms. Plant Cell, 9(2): 261-270.

Silva, M.G.; Costa, R.A.; Ferrarese, M.L.L. \& Ferrarese-Filho, O. (1996), Efeitos de compostos fenólicos sobre a atividade da urease de soja. Arq. Biol. Tecnol., 39(3): 677-683.

Smith, M.T. (1996), The mechanism of benzene-induced leukemia: A hypothesis and speculations on the causes of leukemia. Environ. Health Perspect., 104(6): 12191225.

Torti, S.D.; Dearing, M.D. \& Kursar, T.A. (1995), Extraction of phenolic compounds from fresh leaves: a comparison of methods. J. Chem. Ecol., 21(2): 117-125.

Vanwyk, B.E.; Winter, P.J.D. \& Buys, M.H. (1997), The major flower anthocyanins of Lobostemon (Boraginaceae). Biochem. Syst. Ecol., 25(1): 39-42.
Zamora, F.; Luengo, G.; Margalef, P.; Magrina, M. \& Arola, L. (1995), Effect of drawing off on colour and phenolic compounds composition of red wine. Rev. Esp. Cienc. Tecnol. Alim., 34(6): 663-671.

Zhang, X.H. \& Chiang, V.L. (1997), Molecular cloning of 4-coumarate:coenzyme A ligase in loblolly pine and the roles of this enzyme in the biosynthesis of lignin in compression wood. Plant Physiol., 113(1): 65-74.

Received: October 06, 1997; Revised: November 07, 1997; Accepted: May 12, 1998. 